\title{
Reliability and Validity of the Turkish Version of the Glasgow-Edinburgh Throat Scale: Use for a Symptom Scale of Globus Sensation in Turkish Population
}

\author{
Original Investigation $>\begin{aligned} & \text { Müge Özçelik Korkmaz }{ }^{1} \text { (D), Arzu Tüzüner² (D), Melike Bahçecitapar }{ }^{3} \text { (D), Cengiz Karacaer }{ }^{4} \text { (D) } \\ & \text { 'Department of Otorhinolaryngology, Sakarya University School of Medicine Korucuk Training and Research Hospital, Sakarya, Turkey }\end{aligned}$ \\ ${ }^{2}$ Department of Otorhinolaryngology, Başkent University School of Medicine, Ankara, Turkey \\ ${ }^{3}$ Department of Statistics, Hacettepe University School of Sciences, Ankara, Turkey \\ ${ }^{4}$ Department of Gastroenterology, Sakarya University School of Medicine Training and Research Hospital, Sakarya, Turkey
}

Abstract

ORCID IDs of the authors: M.Ö.K. 0000-0003-4726-7987; A.T. 0000-0001-9735-3504; M.B. 0000-0002-5443-6278; C.K. 0000-0002-7164-4810.

Cite this article as: Korkmaz MÖ, Tüzüner A, Bahçecitapar M, Karacaer C. Reliability and Validity of the Turkish Version of the Glasgow-Edinburgh Throat Scale: Use for a Symptom Scale of Globus Sensation in Turkish Population. Turk Arch Otorhinolaryngol 2020; 58(1): 41-7.

\section{Corresponding Author:}

Müge Özçelik Korkmaz, ozcelikmuge@gmail.com

Received Date: 15.08.2019

Accepted Date: 20.11.2019

Content of this journal is licensed under a Creative Commons Attribution 4.0 International License. Available online at www.turkarchotolaryngol.net
Objective: In this study, we aimed to translate the Glasgow-Edinburgh Throat Scale (GETS) into Turkish and test its reliability and validity.

Methods: A total of 69 patients with globus sensation and no signs of otolaryngologic or gastroenterological disease in etiology were included in the study. The patients were asked to complete the translated Turkish version (GETS-T) of GETS and the Hospital Anxiety and Depression Scale (HADS).

Results: The Cronbach's alpha coefficient of the patients in the study group was calculated based on the 12 questions in the GETS-T scale and found as 0.868. The cor- relation between the GETS-T total score and the total HADS score in the study group was found to be very low and statistically insignificant. As a result of factor analysis, it was found that the first 10 problems in GETS-T were divided into two sub-groups, unlike GETS.

Conclusion: Translation of GETS into Turkish (GETS-T) showed high reliability and validity, suggesting that translation and cross-cultural adaptation was appropriate. The GETS-T can be used in studies about globus pharyngeus in future.

Keywords: Globus sensation, larynx, deglutition disorders, reliability and validity, patient health questionnaire

\section{Introduction}

Globus sensation may be defined as a feeling of something stuck or a lump in the throat without dysphagia or odynophagia (1). Research shows that more than $45 \%$ of the general population experience globus sensation once in their lifetime. Four to six percent of patients who present to Ear Nose Throat (ENT) clinics are globus sensation patients $(1,2)$. In addition, these patients also present to gastroenterology or psychiatry outpatient clinics. Globus sensation may occur due to several reasons. It can be functional, psychological or mass-based. Functional swallowing disorders, laryngopharyngeal reflux, lingual tonsil hypertrophy, epiglottis cysts, benign or malignant larynx and pharynx neoplasms, and dysplasia disorders are the major causes in etiology (3-5). Most of these patients do not have an underlying organic cause and their condition is associated with a psychosomatic disorder (6). The etiological causes of a globus sensation should be assessed and inves- tigated on individual basis since it is the common name of a symptom rather than a specific disease. Therefore, these patients should be evaluated with a multidisciplinary approach when necessary in order to reveal the underlying conditions.

It may not always be easy for the clinician to evaluate the patient's complaints of pharyngeal globus sensation. Difficulties may arise in determining the severity of the symptoms and monitoring the results of the treatment. Therefore, Deary et al. (7) developed the Glasgow-Edinburgh Throat Scale (GETS) about common throat symptoms. The GETS is a 12-item questionnaire consisting of three subscales on globus sensation, dysphagia and pain/swelling in the throat. Unfortunately, this form is not commonly used in daily ENT practice although its validity and reliability has been demonstrated in studies. The GETS was first translated by Takahashi et al. (8) into Japanese and their validity study demonstrated the Japanese version to be safe. 
Our study aimed to evaluate the validity and adequacy of the Turkish version of GETS Form (GETS-T) through statistical methods in order to enable using the GETS-T form in the evaluation and the follow-up of patients presenting especially to the ENT outpatient clinics with globus sensation. The availability of the Turkish version of the GETS will provide convenience and reliability for further studies in the field.

\section{Methods}

Our study was planned as a double-centered prospective study. Pre-study approval was obtained from the Secretariat of the Ethics Committee of Sakarya University School of Medicine (No: 71522473/050.01.04/112, January 2, 2019). As the initial step, permission was requested from Prof. Deary for the translation of the GETS form into Turkish and he kindly granted us the necessary permission. The article was translated from English into Turkish by three independent authors who have very good command of both languages. The translated version was verified with the back-translations of independent translators. The translators were briefed about the purpose of questionnaire. The independent translators compared the original English form with the back-translated forms. Finally, the translated version of the form was revised and approved by all authors. Prior to the commencement of the study, a preliminary trial was carried out with a group of 15 patients who had complaints of globus sensation in order to assess the appropriateness of the questionnaire and the comprehensibility of its language. Responses to the questionnaire were found to be sufficient for symptomatic evaluation.

A total of 69 patients, aged above 18 years, who presented to the ENT departments of Sakarya University Training and Research Hospital and Başkent University School of Medicine Hospital with complaints of feeling of a stuck foreign body were enrolled into our study. In all patients, detailed anamnesis was carried out and detailed ENT examinations, including flexible endoscopic examination, were performed and recorded. Patients with a history of neurologic and chronic rheumatologic disease, prominent upper respiratory tract infection, a significant lesion in the oropharynx, hypopharynx or larynx, and/or with prominent symptoms of reflux laryngitis were excluded from the study. Patients with gastroenterological diseases were also excluded from the study.

The original GETS form in English and its translation into Turkish are shown in Figure 1. Informed consent forms were obtained from the patients who were enrolled in the study and patients were asked to fill out the GETS-T form. In this assessment questionnaire, comprised of 12 items in total, patients were asked to score their throat complaints on a scale of 0 to 7 (none to unbearable) in the first 10 items (Q1-Q10). In the last two items (Q11, Q12), the effects of the complaints of the patients on their life quality were evaluated and patients were also asked to score these questions in the range of 0-7 (no effect to always/extremely). The 10 items of the GETS-T (Q1-Q10) address common throat symptoms and the last two (Q11, Q12) address somatic distress, measuring each patient's reaction to their throat. In addition, the Turkish version of the
Hospital Anxiety and Depression Scale (HADS) (9) was filled out by the patients in order to evaluate their comorbid depressive and anxiety condition and examine its effect on the GETS-T scale score.

The data obtained were evaluated statistically by taking into consideration the previous conformity studies defined in the literature. The relationship between GETS-T and HADS scores of patients was also statistically analyzed.

\section{Statistical Analysis}

A principal component analysis was performed to examine the factorial structure of the GETS-T questionnaire and to identify its subscales. The validity of GETS-T was determined using exploratory factor analysis. The corrected item-total correlations and Cronbach's alpha (if item deleted) for each item of

\section{Throat Questionnaire \\ (Boğaz Anketi)}

Do you have any of the following throat sensations?

(Aşağıda belirtilen boğaz belirtilerinden herhangi biri sizde var mı?)

Please indicate by circling the figure which best describes how much you are affected

(Sizi ne kadar etkilediğine dair en uygun olan şıkkı lütfen daire içine alınız)

Answer all items please

(Lütfen bütün soruları cevaplayınız)

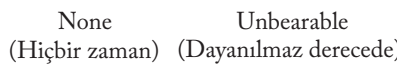

1. Feeling of something stuck in the throat $\quad \begin{array}{llllllll}0 & 1 & 2 & 3 & 4 & 5 & 6 & 7\end{array}$

(Boğazda bir şeyler takılıyormuş hissi)

2. Pain in the throat

(Boğazda ağrı)

3. Discomfort/irritation in the throat

(Boğazda rahatsızlık/tahriş)

4. Difficulty in swallowing food

(Yiyecekleri yutmada zorluk)

5. Throat closing off

(Boğazda kapanma)

6. Swelling in the throat

(Boğazda şişme)

7. Catarrh down throat

(Boğazdan aşağı doğru akıntı)

8. Can't empty throat when swallowing

(Yutkunma sırasında boğazı boşaltamamak)

9. Want to swallow all the time

(Sürekli yutkunma isteği)

10. Food sticking when swallowing

(Yutkunma sırasında yiyecek takılması)

11. How much time do you spend thinking 0

about your throat?

(Boğaz ile ilgili düşünürken ne kadar zaman harciyorsun?)

12. At present, how annoying do you find your throat sensation?

(Şu anda, boğazınızdaki hissi ne kadar sinir bozucu buluyorsunuz?)

Figure 1. The Glasgow-Edinburgh Throat Scale and its Turkish translation (GETS-T) 
the GETS-T scale were calculated to assess the reliability of GETS-T. Spearman's correlation coefficient $\left(r_{\mathrm{s}}\right)$ was used to measure the strengths and the directions of correlations among the 10 throat-related questions (Q1-Q10) in GETS-T and the correlations between the throat-related questions (Q1-Q10) and the last questions (Q11, Q12) assessing the patients reactions to their throats. As in the original study of Deary et al. (7) and its Japanese version by Takahashi et al. (8), the relationships among psychiatric comorbidities of patients, the GETS-T total score, the subscales of GETS-T and somatic distress were also investigated using correlation analysis. Comparisons between male and female patients were analyzed with the Mann-Whitney test. Data were expressed as mean \pm standard deviation (SD and min-max). All statistical analyses were performed using Statistical Package for the Social Sciences Statistics (SPSS) version 21.0 (IBM SPSS Corp.; Armonk, NY, USA). A value of $\mathrm{p}<0.05$ was considered statistically significant.

\section{Results}

\section{Demographic Data}

Table 1 shows the age and gender distributions of the patients enrolled in the study together with their GETS-T and HADS scores. In the study group, there were $52(75.4 \%)$ females and $17(24.6 \%)$ males. There was no difference between the mean ages of the two gender groups ( $p>0.05$ ). Similarly, no statistically significant difference was found between the mean scores of GETS-T (total score) and HADS (total score) in both gender groups $(p>0.05)$. When HADS scores of the patients were evaluated separately in relation to Anxiety and Depression, no statistically significant difference was found between the mean score values of the two gender groups ( $p>0.05)$.

Figure 2 shows the comparison of the mean scores for each item (Q1-Q10) in GETS-T and GETS. Mean scores of GETS were taken from Deary et al. (7). We observed that GETS-T scores were substantially higher than the GETS scores for all questions.

In the first 10 items regarding the evaluation of symptoms, Q1 (Something stuck) and Q3 (Discomfort/irritation) had the highest mean score values. They were followed by Q9 (Want to swallow) and Q8 (Can't empty), respectively. The mean values of Q11 (How much time do you spend thinking about your throat) and Q12 (How annoying is your sensation) questions, which were asked to evaluate the discomfort feeling of the patients, were all above 4 .

\section{Reliability Analysis}

The Cronbach's alpha coefficient $(\alpha)$ of the patients in the study group, calculated based on the 12 items of the GETS-T scale was highly reliable $(\alpha>0.8)$. It can be suggested that the 12 items can be used to calculate the GETS-T and this scale is reliable. Moreover, the results for item-total correlation values were above 0.30 , and this suggests that the items are sufficient to distinguish the measured characteristics (Table 2).

\section{The Correlation between GETS-T and HADS Scores}

The correlation between the GETS-T total score and the total HADS score in the study group was very low and statistically insignificant $\left(\mathrm{r}_{\mathrm{s}}=0.17, \mathrm{p}>0.05\right)$. In Table 3 , however, the correla-

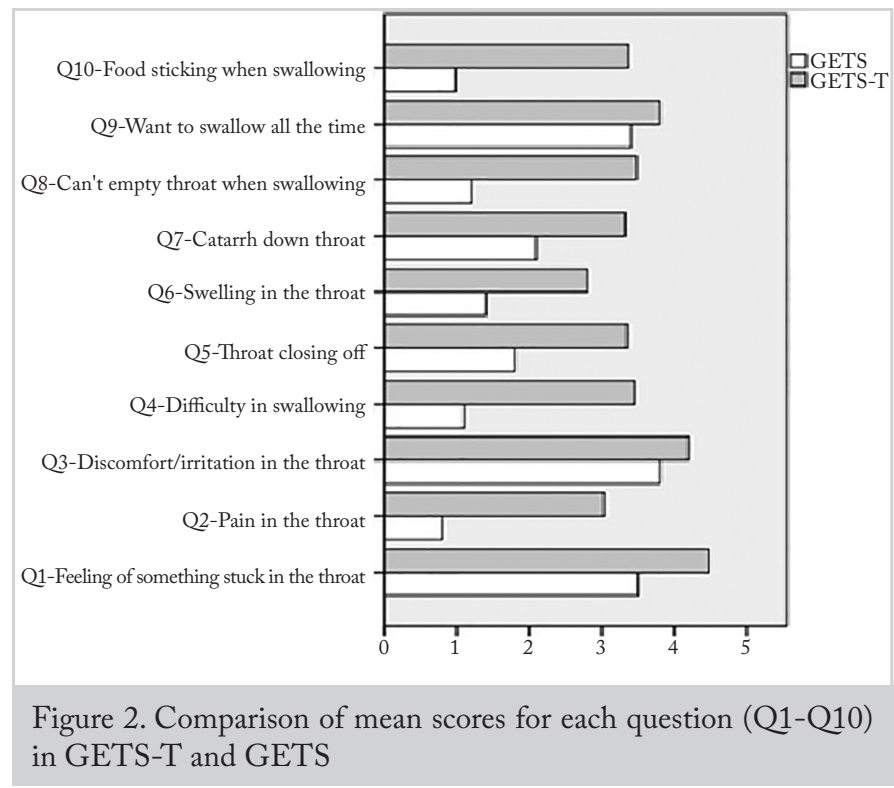

Table 1. Descriptive statistics of patients

\begin{tabular}{|c|c|c|c|c|c|c|}
\hline & & AGE & $\begin{array}{c}\text { GETS-T } \\
\text { (Total Score) }\end{array}$ & $\begin{array}{c}\text { HADS } \\
\text { (Total Score) }\end{array}$ & $\begin{array}{l}\text { Anxiety } \\
\text { HADS }\end{array}$ & $\begin{array}{c}\text { Depression } \\
\text { HADS }\end{array}$ \\
\hline & n (\%) & $\begin{array}{l}\operatorname{mean} \pm S D \\
(\min -\max )\end{array}$ & $\begin{array}{l}\operatorname{mean} \pm S D \\
(\min -\max )\end{array}$ & $\begin{array}{l}\operatorname{mean} \pm S D \\
(\min -\max )\end{array}$ & $\begin{array}{l}\operatorname{mean} \pm S D \\
(\min -\max )\end{array}$ & $\begin{array}{l}\operatorname{mean} \pm \mathrm{SD} \\
(\min -\max )\end{array}$ \\
\hline \multirow[t]{2}{*}{ Study Group(Total) } & \multirow[t]{2}{*}{$69(100)$} & $47.61 \pm 13.38$ & $43.36 \pm 13.37$ & $9.75 \pm 7.03$ & $5.19 \pm 3.72$ & $4.57 \pm 3.78$ \\
\hline & & $(32-76)$ & $(12-75)$ & $(1-26)$ & $(0-14)$ & $(0-16)$ \\
\hline \multirow[t]{2}{*}{ Female } & \multirow{2}{*}{$52(75.4)$} & $48.88 \pm 12.08$ & $44.52 \pm 13.55$ & $9.31 \pm 6.17$ & $4.98 \pm 3.44$ & $4.33 \pm 3.28$ \\
\hline & & $(20-77)$ & $(12-75)$ & $(1-25)$ & $(0-14)$ & $(0-14)$ \\
\hline \multirow[t]{3}{*}{ Male } & \multirow[t]{2}{*}{$17(24.6)$} & $43.71 \pm 16.56$ & $39.82 \pm 12.53$ & $11.12 \pm 9.28$ & $5.82 \pm 4.52$ & $5.29 \pm 5.06$ \\
\hline & & $(24-72)$ & $(19-61)$ & $(2-26)$ & $(1-14)$ & $(1-16)$ \\
\hline & Difference (p) & 0.210 & 0.256 & 0.978 & 0.788 & 0.978 \\
\hline
\end{tabular}


tions between the scores of items Q9, Q11 and Q12 for the GETS-T and the total HADS scores were found to be positive and statistically significant $(\mathrm{p}<0.05, \mathrm{p}<0.01)\left(\mathrm{r}_{\mathrm{s}}=0.24\right.$ for $\mathrm{Q}$, $r_{s}=0.40$ for Q11 and $r_{s}=0.27$ for Q12). Total HADS scores were also found high in patients whose scores were high for GETS-T items Q9, Q11 and Q12 (Table 3).

\section{The Correlation between GETS-T Items}

Table 4 shows Spearman's rho correlation coefficients among Q1Q12 for GETS-T. The correlations were found to be positive and above 0.12 , except for the correlation between $\mathrm{Q} 2$ and $\mathrm{Q} 11\left(\mathrm{r}_{\mathrm{S}}=-0.03\right.$, $p>0.05)$. Correlations above 0.24 were found significant $(p<0.05)$.

Some correlations among the items were substantially higher than others, as shown in Table 5. In order to identify the questions that tend to be correlated, factor analysis with Promax rotation was used with the assumption of correlation between factors or subgroups of questions. In Table 6, the results are

Table 2. Item-total statistics for GETS-T

\begin{tabular}{l|c|c}
\hline Items & $\begin{array}{c}\text { Corrected } \\
\text { item-total } \\
\text { correlation }\end{array}$ & $\begin{array}{c}\text { Cronbach's alpha } \\
\text { coefficient } \\
\text { if item deleted }\end{array}$ \\
\hline Q1 & $0.74^{*}$ & 0.850 \\
\hline Q2 & $0.52^{*}$ & 0.864 \\
\hline Q3 & $0.65^{*}$ & 0.856 \\
\hline Q4 & $0.71^{*}$ & 0.852 \\
\hline Q5 & $0.73^{*}$ & 0.850 \\
\hline Q6 & $0.53^{*}$ & 0.864 \\
\hline Q7 & $0.47^{*}$ & 0.868 \\
\hline Q8 & $0.62^{*}$ & 0.859 \\
\hline Q9 & $0.80^{*}$ & 0.844 \\
\hline Q10 & $0.68^{*}$ & 0.854 \\
\hline Q11 & $0.57^{*}$ & 0.861 \\
\hline Q12 & $0.64^{*}$ & 0.856 \\
\hline "p<0.05 & & \\
\hline
\end{tabular}

shown only for factors with eigenvalues greater than 1 . The first rotated factor had high loadings on Q10 (food sticking when swallowing), Q5 (throat closing off), Q4 (difficulty in swallowing), Q7 (catarrh down throat), Q9 (want to swallow all the time), Q8 (can't empty throat when swallowing) and Q3 (discomfort/irritation in the throat). The second rotated factor had two very high loadings on Q11 and Q12 representing the somatic distress. The third rotated factor had high loadings on Q2 (pain in the throat), Q6 (swelling in the throat) and Q1 (feeling of something stuck in the throat). Most of the other loadings on three factors were very small, i.e., below 0.50 .

We observed that the three orthogonal factors accounted for approximately $41.6 \%, 11.27 \%$ and $9.91 \%$ of the common variances, respectively. The reliability of the total GETS-T score and the scores of its three subscales was revealed by Cronbach's alpha coefficient. The Cronbach's alpha coefficients were 0.867 , $0.833,0.759$ and 0.755 , respectively. These reliability estimates

Table 3. Spearman's rho $\left(\mathrm{r}_{\mathrm{s}}\right)$ correlations between HADS (total score) and GETS-T scale item

\begin{tabular}{l|c}
\hline & rS \\
\hline Q1 & 0.13 \\
\hline Q2 & -0.08 \\
\hline Q3 & -0.06 \\
\hline Q4 & 0.12 \\
\hline Q5 & 0.09 \\
\hline Q6 & 0.09 \\
\hline Q7 & -0.04 \\
\hline Q8 & 0.17 \\
\hline Q9 & $0.24^{*}$ \\
\hline Q10 & 0.08 \\
\hline Q11 & $0.40^{* *}$ \\
\hline Q12 & $0.27^{*}$ \\
\hline p $<0.05$ & \\
\hline$*$ p $<0.01$ & \\
\hline
\end{tabular}

Table 4. Spearman's rho $\left(\mathrm{r}_{\mathrm{S}}\right)$ correlations among the 12 items (Q1-Q12) of GETS-T

\begin{tabular}{|c|c|c|c|c|c|c|c|c|c|c|c|c|}
\hline & Q1 & Q2 & Q3 & Q4 & Q5 & Q6 & Q7 & Q8 & Q9 & Q10 & Q11 & Q12 \\
\hline Q2 & $0.51^{* *}$ & - & & & & & & & & & & \\
\hline Q3 & $0.45^{* *}$ & $0.29^{*}$ & - & & & & & & & & & \\
\hline Q4 & $0.43^{* *}$ & $0.33^{* *}$ & $0.36^{* *}$ & - & & & & & & & & \\
\hline Q5 & $0.45^{* *}$ & $0.33^{* *}$ & $0.37^{* *}$ & $0.58^{* *}$ & - & & & & & & & \\
\hline Q6 & $0.39^{* *}$ & $0.59^{* *}$ & 0.08 & 0.23 & $0.27^{*}$ & - & & & & & & \\
\hline Q7 & 0.13 & 0.23 & $0.34^{* *}$ & 0.23 & $0.29^{*}$ & $0.35^{* *}$ & - & & & & & \\
\hline Q8 & $0.38^{* *}$ & 0.16 & $0.27^{*}$ & $0.32^{* *}$ & $0.43^{* *}$ & 0.18 & 0.19 & - & & & & \\
\hline Q9 & $0.49^{* *}$ & $0.27^{*}$ & $0.46^{* *}$ & $0.53^{* *}$ & $0.54^{* *}$ & $0.31^{* *}$ & $0.33^{* *}$ & $0.45^{* *}$ & - & & & \\
\hline Q10 & $0.28^{*}$ & $0.26^{*}$ & $0.36^{* *}$ & $0.54^{* *}$ & $0.57^{* *}$ & 0.09 & $0.31^{* *}$ & $0.46^{* *}$ & $0.50^{* *}$ & - & & \\
\hline Q11 & $0.43^{* *}$ & -0.03 & $0.24^{* *}$ & $0.30^{*}$ & $0.32^{* *}$ & 0.12 & 0.09 & 0.22 & $0.38^{* *}$ & $0.28^{*}$ & - & \\
\hline Q12 & $0.54^{* *}$ & 0.18 & $0.33^{* *}$ & $0.35^{* *}$ & $0.25^{*}$ & 0.19 & 0.12 & 0.21 & $0.46^{* *}$ & $0.31^{* *}$ & $0.57^{* *}$ & - \\
\hline
\end{tabular}


were above 0.75. Table 6 shows Spearman's rho correlation coefficients among the scores of 3 subscales, GETS-T (Total), Anxiety scale of HADS and Depression scale of HADS. The first subscale (Q3, Q4, Q5, Q7, Q8, Q9, Q10) was highly correlated with the total GETS-T score $\left(\mathrm{r}_{\mathrm{s}}=0.94, \mathrm{p}<0.01\right)$, positively but lowly correlated $\left(\mathrm{r}_{\mathrm{S}}=0.42, \mathrm{p}<0.01\right)$ with the second subscale (Q11, Q12) and positively but moderately correlated with the third subscale (Q1, Q2, Q6). No significant correlation was found among the first subscale, Anxiety scale of HADS $\left(\mathrm{r}_{\mathrm{s}}=0.09, \mathrm{p}>0.05\right)$ and Depression scale of HADS $\left(\mathrm{r}_{\mathrm{S}}=0.11, \mathrm{p}>0.05\right)$. The second subscale (Q11, Q12) was lowly or moderately and positively correlated with the first and the third subscales, total GETS-T score, Anxiety scale of HADS and Depression scale of HADS $\left(r_{s}>0.29, \mathrm{p}<0.01, \mathrm{p}<0.05\right)$. The third subscale (Q1, Q2, Q6) was positively but moderately correlated with the first subscale $\left(\mathrm{r}_{\mathrm{s}}=0.51, \mathrm{p}<0.01\right)$ and total GETS-T score $\left(\mathrm{r}_{\mathrm{s}}=0.70, \mathrm{p}<0.01\right)$ and lowly correlated with the second subscale $\left(r_{\mathrm{s}}=0.29, \mathrm{p}<0.05\right)$. Anxiety HADS scores and depression HADS scores were significantly correlated with each other $\left(\mathrm{r}_{\mathrm{S}}=0.68, \mathrm{p}<0.01\right)$ and the scores of the second subscale $\left(\mathrm{r}_{\mathrm{s}}=0.35\right.$ and $\left.0.33, \mathrm{p}<0.01\right)$.

Table 5. Factor analysis with Promax rotation of the scores for the 12 questions (Q1-Q12) of GETS-T

\begin{tabular}{l|c|c|c|c}
\hline Items & Mean \pm SD & $\begin{array}{c}\text { Rotated } \\
\text { Factor 1 }\end{array}$ & $\begin{array}{l}\text { Rotated } \\
\text { Factor 2 }\end{array}$ & $\begin{array}{c}\text { Rotated } \\
\text { Factor 3 }\end{array}$ \\
\hline Q1 & $4.48 \pm 1.50$ & 0.061 & 0.493 & 0.511 \\
\hline Q2 & $3.04 \pm 1.59$ & 0.122 & -0.242 & 0.894 \\
\hline Q3 & $4.20 \pm 1.54$ & 0.561 & 0.128 & 0.069 \\
\hline Q4 & $3.45 \pm 1.94$ & 0.656 & 0.107 & 0.049 \\
\hline Q5 & $3.35 \pm 1.81$ & 0.753 & -0.003 & 0.068 \\
\hline Q6 & $2.80 \pm 1.72$ & -0.155 & 0.098 & 0.877 \\
\hline Q7 & $3.32 \pm 1.75$ & 0.650 & -0.345 & 0.145 \\
\hline Q8 & $3.48 \pm 1.91$ & 0.586 & 0.166 & -0.080 \\
\hline Q9 & $3.80 \pm 2.07$ & 0.612 & 0.231 & 0.090 \\
\hline Q10 & $3.36 \pm 1.94$ & 0.924 & -0.021 & -0.243 \\
\hline Q11 & $4.01 \pm 1.66$ & 0.003 & 0.922 & -0.177 \\
\hline Q12 & $4.07 \pm 1.45$ & -0.009 & 0.848 & 0.055 \\
\hline \% of common variance & 41.60 & 11.27 & 9.91 \\
explained & & & &
\end{tabular}

\section{Discussion}

In the present study, the Turkish version of GETS was found to have strong reliability and validity. Our study is the second study in which the GETS form was translated into a foreign language after the original version. The Turkish translation of the questionnaire provides the first questionnaire form in Turkish for the evaluation of globus sensation where the cross-cultural adaptation and validity is shown.

Globus sensation is a term for symptoms rather than a particular disease, and patients with these complaints present to various departments, especially the ENT department. Its actual prevalence is considerably higher in the general population as a large number of people fail to present to the hospital for such complaints. A study by Ali and Wilson (10) found that up to $78 \%$ of patients presenting to non-ENT clinics had globus-type symptoms. Deary et al. (7) developed the Glasgow-Edinburgh Throat Scale (GETS) for the evaluation of the symptoms in these patients, and the GETS was used for evaluations in further studies $(10,11)$. However, no detailed study on the prevalence and evaluation in this particular field was available in Turkey to date. One reason for this is that an objective assessment of the patient is difficult under day-time clinic conditions. Our study is also significant as it serves as a preliminary version for such studies.

The majority of the patients in our study were women, which was consistent with the literature. Another remarkable point was that the mean age of the patients was above 45 , similar to other studies $(12,13)$. In our study, the mean value of the total GETS-T scores of the study patients was found to be higher than the mean value of their original GETS scores $(p<0.05)$. The highest values for symptomatic evaluation of the patients were observed to be related to Q1 (feeling of something stuck in the throat) and Q3 (discomfort/irritation).

When the relationship between the GETS-T and the HADS scores was evaluated in our study, no statistically significant correlation was found between the GETS-T scale scores and the total HADS scale scores $\left(r_{s}=0.17, p>0.05\right)$. Contrary to the popular belief, it is important to show that these patients may not always have anxiety and depression symptoms. In terms of the questions, however, positive and statistically significant correlations were found between the scores for the questions on the

Table 6. Spearman's rho $\left(\mathrm{r}_{\mathrm{S}}\right)$ correlations among three subscales of GETS-T, GETS-T (total), Anxiety HADS and depression HADS

\begin{tabular}{|c|c|c|c|c|c|c|}
\hline & $1^{\text {st }}$ subscale & $2^{\text {nd }}$ subscale & $3^{\text {rd }}$ subscale & & & GETS-T \\
\hline & $(\mathrm{Q} 3,4,5,7,8,9,10)$ & $(\mathrm{Q} 11,12)$ & $(\mathrm{Q} 1,2,6)$ & HADS Anxiety & HADS Depression & (Total Score) \\
\hline $1^{\text {st }}$ subscale $(\mathrm{Q} 3,4,5,7,8,9,10)$ & - & & & & & \\
\hline $2^{\text {nd }}$ subscale $(\mathrm{Q} 11,12)$ & $0.42^{* *}$ & - & & & & \\
\hline $3^{\text {rd }}$ subscale $(\mathrm{Q} 1,2,6)$ & $0.51^{* *}$ & $0.29^{*}$ & - & & & \\
\hline HADS Anxiety & 0.09 & $0.35^{* *}$ & 0.02 & - & & \\
\hline HADS Depression & 0.11 & $0.33^{* *}$ & 0.07 & $0.68^{* *}$ & - & \\
\hline GETS-Td (Total Score) & $0.94^{* *}$ & $0.58^{* *}$ & $0.10^{* *}$ & 0.11 & 0.16 & - \\
\hline
\end{tabular}


evaluation of somatic distress (Q11 and Q12) and the HADS scale $\left(r_{\mathrm{s}}=0.40\right.$ for $\mathrm{Q} 11$ and $\mathrm{r}_{\mathrm{s}}=0.27$ for $\left.\mathrm{Q} 12, \mathrm{p}<0.05, \mathrm{p}<0.01\right)$. In other words, patients with a high level of globus complaints have high levels of anxiety and depression levels. Similar findings were found in both of the previous studies, and it was suggested that unresponsive globus complaint could cause anxiety and depression in patients $(7,8)$.

In our study, the Cronbach's alpha coefficient for the evaluation of reliability analysis of the GETS-T questionnaire was found 0.868 and adequately high for reliability. Further, the item-total correlations for each question were greater than 0.30 , and the deleted-item internal consistency coefficients were not greater than 0.868 for Cronbach's alpha coefficients that were calculated on all questions, which indicated the reliability of GETS-T. In the GETS-T questionnaire, questions were seen to be divided into three subgroups based on factor analysis. Principal component factor analysis was performed to determine the construct validity of GETS-T and KMO 0.821, Bartlett test $\chi^{2}$ value of 324.180 ( $\mathrm{df}=66, \mathrm{p}<0.001)$ were found. Accordingly, items Q3, Q4, Q5, Q7, Q8, Q9 and Q10 formed a group and items Q11 and Q12 formed another group, whereas items Q2, Q6 and Q1 formed another group. The coefficient of internal consistency was found to be 0.833 for the first subscale, 0.759 for the second subscale and 0.755 for the third subscale. As a result of the exploratory factor analysis and internal consistency analysis for the adaptation of GETS into Turkish, it can be suggested that GETS-T is a reliable and valid measurement tool for throat symptoms.

In this study, the categorization of questions into sub-groups differed from the previous two studies $(7,8)$. In GETS-J, principal component analysis identified Q1, Q5, Q9 as globus scale and Q2, Q3, Q6 as pain/swelling scale, whereas the GETS identified Q1, Q3, Q9 as globus scale and Q2, Q5, Q6 as pain/ swelling scale. Dysphagia scale consisted of Q4, Q8, Q10 in both GETS-J and GETS. Items Q11 and Q12 were evaluated separately in both studies. From this perspective, when we also evaluated items Q11 and Q12 separately in our study, we found that the questions did not show a similar distribution to the previous two studies. Therefore, it can be suggested that the items in our study can only be divided into dysphagia and pain/swelling groups. This may be linked to the fact that the patients gave higher scores, i.e., generally 3 or above, to questions compared to the first study (Figure 2). Turkish patients describe their globus complaints in a different way than those described in the UK and Japan and experience their complaints more intensely. We believe that further studies using this questionnaire will provide more detailed information about the social differences in globus symptoms.

All items of GETS-T, except Q2 and Q11, had positive correlations with each other. However, all correlation coefficients were not statistically significant. Total GETS-T scores of patients with higher complaints on globus were also higher. However, no significant relationship was found among the first and third subscales and the HADS. Under ordinary cir- cumstances, a strong relation exists between the questions of the second subscale and the HADS. In this respect it may be suggested that the scores given by the patients to the questions are not associated with personal anxiety level, except in Q11 and Q12. This is important for presenting different data on the correlation between the general known globus sensation and psychosomatic etiology.

\section{Conclusion}

The Turkish version of GETS (GETS-T) has high reliability and validity, suggesting that cross-cultural adaptation is not problematic in GETS-T. Although the incidence of patients with globus sensation is high in the general public, it does not always suffice to just evaluate these patients and to determine the etiological cause. For instance, no conclusive data are available to determine the incidence of globus sensation in the Turkish population. This assessment questionnaire will be useful in future etiological and epidemiological studies to provide an objective and single scale for evaluation. Another contribution of this study is that, contrary to common knowledge, no significant difference exists in the anxiety and depression levels of patients. It will thus be possible to orient these patients more accurately.

Ethics Committee Approval: Ethics committee approval was received for this study from the Ethics Committee of Sakarya University School of Medicine (No: 71522473/050.01.04/112, January 2, 2019).

Informed Consent: Written informed consent was obtained from the patients who participated in this study.

Peer-review: Externally peer-reviewed.

Author Contributions: Concept - M.Ö.K., A.T.; Design - M.Ö.K., A.T.; Supervision - M.Ö.K., A.T., M.B.; Fundings - M.Ö.K., A.T., M.B., C.K.; Materials - M.Ö.K., A.T., C.K.; Data Collection and/ or Processing - M.Ö.K., A.T., M.B.; Analysis and/or Interpretation M.Ö.K., A.T., M.B.; Literature Search - M.Ö.K., A.T., C.K.; Writing M.Ö.K., A.T., M.B., C.K.; Critical Reviews - M.Ö.K., A.T., M.B., C.K

Conflict of Interest: The authors have no conflicts of interest to declare.

Financial Disclosure: The authors declared that this study has received no financial support.

\section{References}

1. Deary IJ, Wilson JA, Kelly SW. Globus pharyngis, personality, and psychological distress in the general population. Psychosomatics 1995; 36: 570-7. [Crossref]

2. Drossman DA, Li Z, Andruzzi E, Temple RD, Talley NJ, Thompson WG, et al. U.S. householder survey of functional gastrointestinal disorders. Prevalence, sociodemography, and health impact. Dig Dis Sci 1993; 38: 1569-80. [Crossref]

3. Färkkilä MA, Ertama L, Katila H, Kuusi K, Paavolainen M, Varis K. Globus pharyngis, commonly associated with esophageal motility disorders. Am J Gastroenterol 1994; 89: 503-8. 
4. Harar RP, Kumar S, Saeed MA, Gatland DJ. Management of globus pharyngeus: Review of 699 cases. J Laryngol Otol 2004; 118: 522-7. [Crossref]

5. Lee BE, Kim GH. Globus pharyngeus: A review of its etiology, diagnosis and treatment. World J Gastroenterol 2012; 18: 2462-71. [Crossref]

6. Moloy PJ, Charter R. The globus symptom. Arch Otolaryngol 1982; 108: 740-4. [Crossref]

7. Deary IJ, Wilson JA, Harris MB, Macdougall G. Globus pharyngis: Development of a symptom assessment scale. J Psychosomatic Res 1995; 39: 203-13. [Crossref]

8. Takahashi N, Kaori M, Hironori B, Takanobu S, Ohno M, Ikarashi $\mathrm{F}$, et al. Reliability and validity of the Japanese version of the Glasgow Edinburgh Throat Scale (GETS-J): Use for a symptom scale of globus sensation. Auris Nasus Larynx 2018; 45: 1041-6. [Crossref]

9. Paker N, Bugdayci D, Midik M, Celik B, Kesiktas N. Reliability of the Turkish version of the hospital anxiety and depression scale in the people with traumatic spinal cord injury. NeuroRehabilitation 2013; 33: 337-41. [Crossref]

10. Ali KH, Wilson JA. What is the severity of globus sensation in individuals who have never sought health care for it? J Laryngol Otol 2007; 121: 865-8. [Crossref]

11. Cathcart RA, Steen N, Natesh BG, Ali KH, Wilson JA. Nonvoice related throat symptomps: Comparative analysis of laryngopharyngeal reflux and globus pharyngeus scales. J Laryngol Otol 2011; 125: 59-64. [Crossref]

12. Timon C, O'Dwyer T, Cagney D, Walsh M. Globus pharyngeus: Long-term follow-up and prognostic factors. Ann Otol Rhinol Laryngol 1991; 100: 351-4. [Crossref]

13. Park KH, Choi SM, Kwon SU, Yoon SW, Kim SU. Diagnosis of laryngopharyngeal reflux among globus patients. Otolaryngol Head Neck Surg 2006; 134: 81-5. [Crossref] 